\title{
КРИТЕРИИ ОТБОРА БЕРЕМЕННЫХ ДЛЯ ПОИСКА МУТАЦИИ В ГЕНЕ GСК (MODY2)
}

\author{
Плеханова М.А.
}

ГБУз МО Московский областной НИИ акушерства и гинекологии, Москва

ЦЕЛЬ: оценка эффективности современного калькулятора для отбора на проведение молекулярногенетического исследования (МГИ) во время беременности

МАТЕРИАЛЫ И МЕТОДЫ: в Исследование были включены ретроспективно 56 беременных с впервые выявленной гипергликемией. Всем женщинам было проведено МГИ с помощью метода высокоэффективного параллельного секвенирования, в лаборатории отделения наследственных эндокринопатий ФГБУ «НМИЦ эндокринологии» МЗ РФ (зав. отд., А.М.Н. Тюльпаков А.Н.). Работа проведена при поддержке гранта РНФ № 16-15-10408. По результатам МГИ пациентки были разделены на 2 группы. В 1-ю группу вошли 39 беременных с ГСД (MODY исключен), по 2-ю группу - 17 беременных с MODY2. Всем беременным проведена оценка Positive Predictive Value («положительное предсказательное значение», PPV), с помощью MOGY Probability Calculator на сайте https://www.diabetesgenes.org/. Критерии калькулятора: возраст, пол, лечение инсулином или пероральными препаратами, время до назначения инсулинотерапии, ИМТ, $\mathrm{HbA}_{1 c^{\prime}}$ наследственность. Критерий исключения: возраст беременной >35 лет (ограничения калькулятора). Данные представлены как медиана (нижний квартиль; верхний квартиль).

РЕЗУЛЬTАТЫ: возраст в группе ГСД 32 [30;33] года, в группе MODY2 24 [28;30] года. ИМТ в группе ГСД

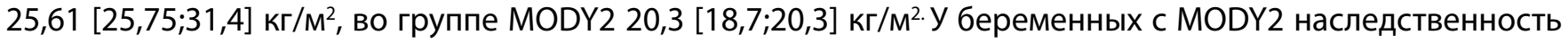
отягощена 13 (17) женщин (76\%), в группе ГСД 18 (39) женщин (46\%). Глюкоза венозной плазмы (ГВП) натощак в группе ГСД 5,7 [5,7;6,0] ммоль/л, $\mathrm{HbA}_{1 c} 5,2$ [5,0;5,6] \%. В группе MODY2 ГВП натощак - 6,2 [5,5;6,6] ммоль/л, НbA 1 - 5,6 [5,4;5,8] \%. В группе MODY2, все пациентки получали инсулинотерапию. В ГСД группе 25 (39) 64\% беременных получали инсулинотерапию. В группе ГСД PPV 49,4 [12,6;49,4] \%, колебания от $7,2 \%$ до $75,5 \%$. Наименьший PPV $(7,2-12,6 \%)$ имели пациентки без отягощенной наследственности, получающие инсулин во время беременности. PPV >70\% имели пациентки с отягощенной наследственностью, в качестве лечения во время беременности получающие только диету. В группе MODY2 PPV 8,2 [7,7;28,8] \%, что значительно меньше, чем в группе ГСД, $\min$ PPV 7,2, max 49,4\%. Пример работы калькулятора у беременной из группы MODY2. Наследственность по СД не отягощена (со слов). Гипергликемия в 1-ю беременность не выявлена, вес первого ребенка при рождении 4050 г/56 см в 39 нед. В 10 недель данной беременности ГВП 6,3 ммоль/л, $\mathrm{HbA}_{1 с}-6,5 \%$. С 13 недель инсулинотерапия в базис-болюсном режиме. Аутоантитела (GAD, ICA, IA-2) - отрицательные. PPV 7,2\%. При расчете с учетом отягощенной наследственность PPV 49,4\%. Также одним из важных критериев калькулятора является инсулинотерапия. Учитывая, что целевые показатели во время беременности более низкие и инсулинотерапия назначается при гликемии натощак >5,1 ммоль/л, через час после еды >7,0 ммоль/л, данный критерий не может быть расценен как предиктор MODY. Калькулятор имеет чувствительность (91\% против 72\%) и специфичность (94\% против 91\%) для определения MODY по сравнению со стандартными критериями диагностики (возраст $<25$ лет и отягощенная наследственность).

Выводы: калькулятор MOGY Probability не может корректно использоваться у беременных. Выбор пациенток для проведения МГИ во время беременности должен носить персонализированный подход, учитывающий клиническую картину, наличие специфических антител и наследственность. 